detent shown in the drawing to fall; this closes the circuit, and a hook attracted by the coil, catches a tooth cut in the escape-wheel, and holds it till the standard clock reaches the hour. At the hour the standard clock, Fig. 10, allows the lower detent to fall, and so breaks the circuit. Consequently the clock, Fig. II, starts off side by side with the standard.

Mr. Ritchie, to whom we have referred before, has also devised a plan for correcting clocks by hourly currents. His clock, to be corrected in like manner, gains some second or two per hour. Fifteen seconds before each hour the lever D B (see Fig. I2) is attracted by the electromagnet $A$, and a pin in the arm $D$ would thereupon enter and catch a tooth of the escape-wheel, did the disc $M$ allow the other arm of the lever $\mathrm{E}$ to move. When the hand reaches the hour, $\mathrm{E}$ falls, then $\mathrm{D}$ catches $\mathrm{S}$ and holds it till the cessation of the current at the sixtieth second of the governing clock.

Generally the use of a long telegraphic wire can only be commanded for a few minutes daily. Fig. 13 shows a very suitable arrangement to be adopted when this is the case. By means of the 24 -hour disc the line wire is held in communication with the telegraph office until a

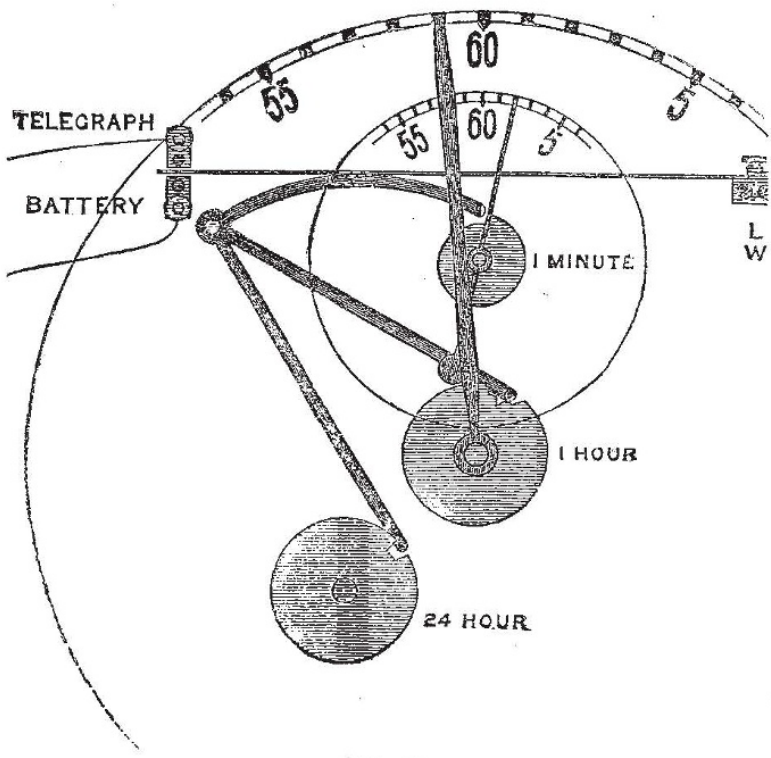

FIG. I3.

few minutes before the clock current is going to be despatched. The notch in the 24 -hour disc will at last allow the system of levers to fall, but then the I-hour disc supports them until about one minute before the clock current is coming; so that, till then, the line is being used for messages. The line wire has not been allowed to fall into circuit with the battery wire; this is still prevented by the I-minute disc. At the sixtieth second precisely the $\mathrm{r}$-minute disc allows the line wire to join the battery wire, and out goes the clock current. Some seconds afterwards the I-hour disc lifts the line wire back into communication with the telegraph office, where it stays for another twenty-four hours.

The Great Westminster Clock reports its own time to Greenwich by the following arrangement:--Some minutes before a signal is due, a lever is lifted by a slow whecl into such a position that a pin in the next wheel at its coming rotation will catch it. The second wheel lifts it so much further that a pin in the escape wheel reaches it, presses two slight springs together, and sends off the signal.

A method of driving an electric dial was contrived by the late E. J. Dent. A powerful magnet was lifted through a coil of insulated wire by a strong tower clock movement. Every half minute the magnet was dropped a current was generated in the coil, which proceeded to the dial and moved the hands. A plan on the same principle bas lately been used for driving a number of small dials. A pendulum having a hollow coil of insulated wire for a bob, is by a heavy weight kept oscillating over a system of mag. nets. Currents are generated in the coil which proceed to the dials and work them.

Only the principal inventions in electrical clocks and clock-work have been indicated in this article. Since the year I 843 upwards of thirty patents have been applied for for improvements in such clocks and clockwork. It will be seen from this the subject, though not a wide one, is extensive.

Mr. Ritchie kindly lent diagrams $5,6,9$, I2, and 13 to illustrate his plans, and M. Collin Io and Ix. Figs. $x$ and 3 have been arranged to exhibit their working with clearness.

HENRY DENT GARDNER

\section{TAUNTON COLLEGE SCHOOL}

WE are sorry to chronicle the extinction of a school once watched with interest by all supporters of scientific education. The company which formed it is insolvent; the school buildings with the fine library and all the collections and apparatus which the late headmaster amassed will be sold for the benefit of the creditors; the shareholders will lose their money; and the town will fall back for its higher education on the old, dilapidated, unhealthy grammar school.

The directors of the company, who constituted the council of the school, have performed no ordinary feat. Four years ago the school was nearly full, its annual profits considerable, its distinctions, and consequent reputation, unprecedented in so young an institution; public lectures in literature and science attracted to its hall large classes from the town and neighbourhood; and its systematic teaching of science to all its pupils was studied and imitated by many other schools. The council exhibited sudden activity; they starved the teachingstaff, interfered with the discipline and management, thwarted, harassed, humiliated the head-master. Warnings from parents and old pupils fell upon them unheeded. The last term of 1877 saw two open scholarships at $\mathrm{Ox}$ ford, two places in Cooper's Hill, and a host of minor honours gained by the boys; but it saw also the headmaster bullied into resignation, and all but a handful of the pupils withdrawn by their indignant friends. The fate of the school was clear to all except the council; it has lingered on only to add to the liabilities of the share holders, who have now met to learn from their directors the history of a great scheme blighted, of insolvency far beyond the value of the mortgaged property, of their ancient school relapsed into the feeble, obsolete, pro. vincial position from which Mr. Tuckwell rescued it.

\section{ON SUPERSATURATION}

A SOLUTION is a case of adhesion overcoming coA hesion; and when these two forces are in equilibrium the solution is said to be saturated.

In general the adhesive force is diminished by lowering the temperature, and a portion of the solid, a salt, for example, is thrown down; but it is increased by raising the temperature, so that the liquid can take up an additional portion of the solid.

In the case of a large number of salts, but for the most part those that are hydrated, a solution saturated at a given high temperature can be reduced to a lower one without depositing any salt, in which case the solution is said to be supersaturated, because it contains more salt than it can take up at the reduced temperature.

For example, 100 parts of water at $194^{\circ} \mathrm{F}$. will 